\title{
Future Prospects and Barriers of Pharmaceutical Industries in Bangladesh
}

\author{
Jesmin Sultana \\ Department of Business Administration, University of Asia Pacific, 74/A Green Road, \\ Dhaka-1215, Bangladesh
}

Received: December 26, 2015; Accepted: January 12, 2016; Published (Web): February 17, 2016

\begin{abstract}
The present study is focused towards the analysis of different barriers and prospects of pharmaceutical industries in Bangladesh. Pharmaceutical industry is one of the most promising sectors in Bangladesh. After the promulgation of local industry friendly Drug (Control) Ordinance in 1982 the scenario of pharmaceutical industries changed considerably. Now, after fulfilling the local demand Bangladesh is exporting pharmaceutical products to over 100 countries of the world. There are still lots of space for Bangladesh to flourish in this sector. So initiatives from the stakeholders are required to ensure the remarkable growth of pharmaceutical industries in Bangladesh. In this study, the scopes of advancement and the factors that can hinder the growth of pharmaceutical business are discussed thoroughly.
\end{abstract}

Key words: Pharmaceutical industry, Bangladesh, pharmaceutical marketing, drug market

\section{Introduction}

The pharmaceutical industries are one of the most promising sectors in Bangladesh which is currently contributing significantly in the country's economy. The Drug (Control) Ordinance in 1982 was the key factor of success of pharmaceutical industries in Bangladesh (Rich, 1994). Two decades ago, most of the drugs needed to be imported. Now, only $3 \%$ of the lifesaving high tech products are imported while the remaining comes from local companies. About 240 pharmaceutical companies are now operating in the country, which are manufacturing about 5,600 brands of medicines in different dosage forms. According to a report of the International Management System (IMS) published in June 2015, the size of the pharmaceutical market of Bangladesh is estimated to be approximate 117 billion taka, with an annual growth rate of about $11.37 \%$ (Hossain and Shoaib, 2014). Bangladesh pharmaceutical industries are the largest white-collar employment sector of the country, which are employing around 115,000 workers. A wide range of pharmaceutical products are being exported to more than 100 countries. The major importers for Bangladeshi medicines are now Myanmar, Sri Lanka and Kenya. The qualities of the products of Bangladesh are equivalent to any international standard and have been accepted by them. A number of companies have achieved accreditation from different world famous regulatory bodies.

Hoq et al. (2013) analyzed the pharmaceutical sector of Bangladesh by using the framework of SWOT (Strength, opportunity, weakness and threat). The study provided some valuable suggestions to overcome the weaknesses and threats and there are still some suggestions to utilize the strengths and opportunities properly. Through this study, the researcher has attempted to discuss the effects of various macroeconomic factors of strength, opportunity, weakness and threat on the industries and its related problems and prospects for the future.

Habib and Alam (2011) tried to identify the major problems of marketing, export, production and 
operations, quality control in the pharmaceutical sector and proposed strategies to overcome these problems. They also identified the prospects of pharmaceutical industries in Bangladesh.

Bhuiyan et al. (2011) studied the challenges and critical success factors of pharmaceutical industries of Bangladesh. The study also suggested establishment of bioequivalence test facilities and foreign investments for further advancement in this sector. The present study has been designed with the following objectives:

- To find out attractiveness of pharmaceutical industries in Bangladesh.

- To analyze the profitability of pharmaceutical industries in Bangladesh.

- To identify the impacts and prospects of pharmaceutical industries.

- To recommend means and ways to overcome the barriers for the development of pharmaceutical sector.

\section{Methodology}

Secondary data from local and international researchers have been collected from several recognized journals, magazine, newspapers and websites. Some information has been collected from discussion with concerned professionals of different pharmaceutical companies. Based on the secondary data, the situation has been analyzed and on this ground personal view according to economical perception is given here.

\section{Discussion}

Prospects

Pharmaceutical market growth potential: The growth of pharmaceutical industries of Bangladesh is remarkable and there are a lot of potentials (Bashar and Islam, 2014). As people are getting educated, they are now more conscious about healthcare. In this regard, we can highlight about the increasing demand of "wellness" drugs, vaccines, medical devices, etc. So the demands of medical products are rising. On the other hand, many local companies are exporting their products to different countries. At this time Bangladesh is exporting medicines to more than 100 countries. Two topmost companies have already received the approval of FDA (Food and Drug Administration, USA), which is milestone for Bangladesh as this approval will open the US market for Bangladeshi pharmaceutical products. Moreover, another 5-7 pharmaceutical industries are upgrading their plants for the FDA inspection and approval. The market size is in increasing trend as depicted in Figure 1 and Table 1.

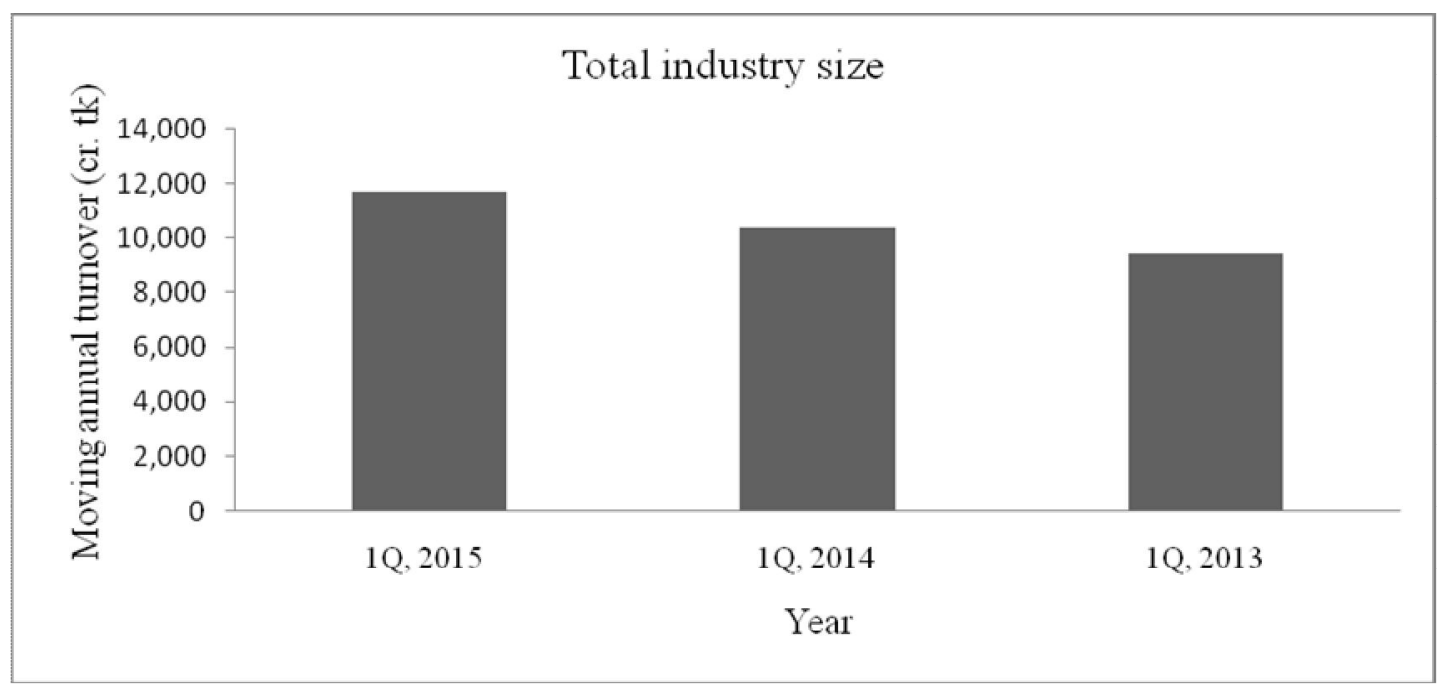

Figure 1. Uptrend of Bangladeshi pharmaceutical industries (Source: IMS, 2015). 
Table 1. Growth of top ten Bangladeshi pharmaceutical companies in last three years (Source: IMS, 2015).

\begin{tabular}{lccc}
\hline Company name & Growth $(\%)$ at $1 \mathrm{Q}$, & Growth $(\%)$ at $1 \mathrm{Q}$, & Growth $(\%)$ at $1 \mathrm{Q}$, \\
\hline 1. SQUARE & 2015 & 2014 & 2013 \\
2. INCEPTA & 6.15 & 14.54 & 7.13 \\
3. BEXIMCO & 14.43 & 14.32 & 12.28 \\
4. OPSONIN & 7.72 & 11.30 & 5.14 \\
5. RENATA & 15.69 & 11.38 & 10.03 \\
6. ARISTOPHARMA & 10.31 & 11.88 & 9.92 \\
7. ESKAYEF & 19.36 & 11.62 & 12.78 \\
8. ACI & 10.20 & 11.21 & 2.60 \\
9. ACME & 6.33 & 12.40 & 3.49 \\
10. DRUG INTERNATIONAL & 9.60 & 14.73 & -1.90 \\
\hline
\end{tabular}

New horizons for pharmaceutical industries: Active pharmaceutical ingredients (API) are the principal constituents for medicines. Unfortunately, major percentage of demand for APIs is fulfilled through import. Though late, government has taken initiatives to build API park for synthesizing pharmaceutical raw materials in Bangladesh. Construction works of API parks are undergoing to start production of drug substances.

Because of increasing demands for different technology based medical products few companies have started to produce medical devices also. This will be another very promising branch of pharmaceutical industries within few years.

Sufficient manpower: Pharmaceutical sector is the largest white-collar demanding employment sector of the country. 12 public and 22 private universities are currently offering Bachelor of Pharmacy (B. Pharm.) and Master of Pharmacy (M. Pharm.) programs (Mazid and Rashid, 2011). A large number of technically skilled personnel are involved in this sector in Bangladesh. This manpower can significantly contribute to global pharmaceutical industries.

\section{Barriers of pharmaceutical industries in Bangladesh}

Tariffs and international trade restrictions: Trade Related Aspects of Intellectual Property Rights (TRIPS) is an international agreement administered by the World Trade Organization (WTO). According to this agreement, all signatory parties are bound to include twenty years product patent protection for pharmaceutical products in their domestic legislation. Previously, the 48 LDCs are not obliged to perform legislation on product patent rights till 2016, which has been extended in late 2015 till 2033. Bangladesh is among these 48 countries. So until 2033, Bangladesh can export to any country if the drug is not under patent or has not implemented product patent protection. Bangladeshi pharmaceutical companies are provided with patent-free production rights domestically until 2033 (after new amendments in 2015) and limited exporting advantage.

Insufficient raw material production facilities: Bangladeshi pharmaceutical sector is involved only in the production of finished products. Almost $80 \%$ of raw materials are now being imported by Bangladesh (Padma, 2011). Local production of APIs (raw materials) will significantly contribute to pharmaceutical sector to extend export volume and also can reduce dependency to other API manufacturing countries.

Absence of bioequivalence test facility: Bioequivalence study is the core of registration of any product in many of the moderately regulated and regulated countries of the world. But Bangladesh is seriously lacking standard facilities for bioequivalence study. Now to register a product, a pharmaceutical company has to carry out this test in a foreign country by spending huge foreign currency. So the stakeholders 
should take initiatives to establish bioequivalence test facilities as soon as possible (www.eblsecurities.com).

Lack of modern drug testing laboratory: Due to lack of well equipped drug testing laboratory, DGDA (Directorate General of Drug Administration) cannot monitor the quality of drugs manufactured by different pharmaceutical companies in Bangladesh. As a result foreign buyers and regulatory authorities sometimes raise questions about the quality of our drug (www.eblsecurities.com). Recently, NCL (National Control Laboratory) has been established and equipped with many modern instruments, but there are very few trained personnel to operate these.

Marketing strategy: Pharmaceutical industries are now in high-end development trend that is being carried out by leading companies. Increasingly, many companies are competing with new pharmaceutical industries. As a result, the success of pharmaceutical industries largely depends on the efficiency and effectiveness of the highly trained and qualified medical promotion officers.

Problems regarding export: The Directorate General of Drug Administration (DGDA) regulates all activities related to import and export of raw materials, packaging materials, production, sale, pricing and licensing. This is the highly credible drug regulatory authority in Bangladesh. But due to lack of adequate manpower and effective training programs they can't execute their duties properly. Continuous training and exchange programs with global regulatory bodies would help them equip with the skills and knowledge to perform their duties more effectively. Apart from that, to be able to operate in regulated markets such as USA, EU or Australia, any pharmaceutical company must have qualified manpower with sufficient knowledge and expertise to deal with increasingly important legal and regulatory issues.

Contest in the Bangladeshi pharmaceutical market: In Bangladeshi pharmaceutical industries there are two types of race, one is for the local market and another one is to catch the generic market by having US FDA approved plant. Essentially, competition in an industries including pharmaceuticals depends on the following factors (Porter, 2008) -
Rivalry among existing firms: Competition among different pharmaceutical industries is increasing day by day (Hoq et al., 2013). When a pharmaceutical company launches new medicine, existing companies are indirectly enforced to produce the same type of medicines to take advantage of the opportunity.

Threat of new entrants: In Bangladeshi pharmaceutical industry, there are many large companies operating their business successfully, like Square, Incepta, Beximco, Opsonin, Renata etc. As a result any new entrants will face tremendous competition with these renowned companies. So it is very difficult for new entrant to capture the market because reliability is a crucial factor in pharmaceutical industries. Again, if new company tries to compete with the existing companies they may have to face the challenge of the competitors having lot of resources.

Threat of substitute products: There are different options to the prescribers and patients in therapeutic situations in Bangladesh. At present, there are 269 allopathic, 205 ayurvedic, 266 unani, 27 herbal and 79 homeopathic drug manufacturing companies operating in the country. As a result patients have a number of choices regarding medication. So, they may perhaps try for substitute one for another.

Bargaining power of buyers: In pharmaceutical industries, the consumers have little bargaining power. In Bangladesh there is a trend of influencing medical practitioners, wholesale and retail shops of pharmaceutical products to promote products. As medication is the most important need for community and price of medicine of all the companies are almost relatively at the same level buyers have little bargaining power.

Bargaining power of suppliers: Bangladeshi pharmaceutical sector is not fully self-sufficient as it is dependent on various countries like China, India, Germany, UK, France, Italy, Denmark, Switzerland, Austria etc., for raw materials. Bangladesh produce insignificant amount of raw materials now (Padma, 2011) but hopefully they will start to produce APIs when the API park becomes fully operational. As a result, the suppliers of APIs of pharmaceutical companies have much bargaining power. 


\section{Recommendations}

The proposed suggestions may help the pharmaceutical industries to minimize the problems in different areas:

- Government has already facilitated pharmaceutical industries by reducing customs duty on raw materials and recently going to start the journey of API park in Munshiganj. These attempts are appreciable but government should take more steps to promote export to different countries.

- Strict application of standard operating procedure in all aspects of production.

- Promoting knowledge based marketing strategy.

- Establishment of bioequivalence test facilities.

- Establishment of CRO (Clinical Research Organization) to conduct clinical trials.

- Practicing strict rules and regulations to fight against counterfeit drugs.

- Making people more health conscious.

- Immediate establishment of hospital pharmacy in every government and private hospitals.

- Export Promotion Bureau (EPB) can play an effective role by arranging international fair frequently.

- Proper selection of raw materials and machineries for better product quality.

- More attention should be given to research and development sector.

- Efficient human resource is the key factor for the growth of any sector. For this, proper training and development programs need to be started in the industries as well as in universities.

\section{Conclusion}

Bangladesh has become almost self-sufficient in ensuring the supply of medicines and pharmaceuticals for local consumption. Only 2-3\% high tech medicines are being imported recently, but our industries have started production of such products. Within a decade we may reduce the import of high tech products. Moreover, Bangladesh is exporting medicines and healthcare products to more than 100 countries, including some developed countries. It is a significant development for Bangladesh that though being a member of the LDC countries, the pharmaceutical products of Bangladesh are competing with the developing and some developed countries. So, there is no doubt regarding the capability of manufacturing quality drugs. There is huge scope of growth in this sector. So, immediate attempts from both government and non-government organizations can make this industrial sector to be more contributing to the economic growth of Bangladesh.

\section{References}

Bashar, S.M. and Islam, M.I. 2014. Determinants of profitability in the pharmaceutical industries of Bangladesh. J. SUB. 5, 56-76.

Bhuiyan, M.A.R., Moniruzzaman and Sultana, S. 2011. Analysis of pharmaceutical industries of Bangladesh: (It's challenges \& critical success factors). Bangladesh Res. Pub. J. 5, 142-156.

Habib, M.A. and Alam, M.Z. 2011. Business analysis of pharmaceutical farms in Bangladesh: problems and prospects. J. Bus. Tech. 6, 61-77.

Hoq, M.R., Ahsan, M.A. and Tabassum, T.A. 2013. Study on SWOT analysis of pharmaceutical industries: The Bangladesh context. Glob. Discl. Econ. Bus. 2, 133-141.

Hossain, M.M. and Shoaib, S.M. 2014. Role of pharmaceutical sector in the national economy of Bangladesh. W. J. Pharm. Pharmaceut. Sci. 3, 951-960.

http://www.eblsecurities.com/report/9fec95fc34f0649c4a5f55 75ead478ed.pdf

Mazid, M.A. and Rashid, M.A. 2011. Pharmacy education and career opportunities for pharmacists in Bangladesh. Bang. Pharm. J. 14, 1-9.

Padma T.V. 2011. Bangladesh eyes the generic pharma pie. Nat. Med. 17, 524.

Porter, M.E. 2008. The five competitive forces that shape strategy. Har. Bus. Rev. 86, 78-93.

Reich, M.R. 1994. Bangladesh pharmaceutical policy and politics. Health Policy Plan 9, 130-143. 